\title{
Hoffman, L.M. \& Schmitter Heisler, B., Short-term rentals and the future of housing, London, New York: Routledge, 2021, 158 pp., ISBN 9780367234188
}

\author{
Marta Tonetta ${ }^{1}$
}

Published online: 28 September 2021

(c) The Author(s), under exclusive licence to Springer Nature B.V. 2021

The slow and uneven control of the pandemic of Covid-19 and the consequent rebound of visitor flows in some of urban and extra-urban contexts across the world has fostered a resurgence of the short-term rental markets, prompting a refocusing of attention on their impacts. Given the role of short-term rentals (STRs hereafter) as perturbators of the local housing markets and the challenges they posit for housing justice, the topic remains a key component of the features of the contemporary housing question it is still essential to investigate.

The book "Short-term Rentals and the Future of Housing" engages with this debate, elaborating on the extent to which STRs affect housing, neighborhoods, and communities with their disruptive effects. By focusing on short-term rentals platforms' major player, Airbnb, and adopting a comparative approach between the US, Germany, and Australia, with four American cities (New York, San Francisco, Los Angeles and Boston), two Australian urban contexts (Melbourne and Sydney) and two German cities (Berlin and Munich), the authors Lily M. Hoffman and Barbara Schmitter Heisler provide an overview of the main features and problematic aspects of the phenomenon, as well as of the local regulatory responses that have been implemented in order to address them.

Throughout the pages, building on a literature review, the authors elaborate on a twofold narrative. First, they analyze the process of commodification and increasing institutionalization of STRs which led to rising rents, residents' displacement, alteration of commercial and demographic fabric in neighborhoods affected by the Airbnb syndrome. Then, through the lens of financialization, they reconstruct the steps which transformed the STRs' market into a system of real-estate-based capital extraction. Such a system, if it offers a large range of profit possibilities for homeowners and investors in relation to various types of housing tenures, also severely harms the right to housing.

Their work is organized as follows. After the preface and the introduction, the book is divided in two parts. The first deals with the American case study. Chapter One focuses on the rise of "sharing" economy, Airbnb and the dynamics of housing financialization. The second chapter addresses the problem of data availability and tells the experiences of data wars that have developed due to Airbnb and STRs platforms' reticence in sharing

Marta Tonetta

marta.tonetta@unito.it

1 Department of Cultures, Politics and Society, University of Turin, Turin, Italy 
information about the features of their markets, especially in terms of quantity and geographies of their listings. In Chapter Three, the authors highlight the negative externalities of the so-called "Airbnb Effect", such as, among others, housing rising prices and rents, racialized gentrification, and displacements of local residents.

Part Two moves beyond the U.S. and presents the cases of Australia (Chapter Four), identified as one of the "Airbnb most penetrated markets" and of Germany, analyzed as an example of one of the "Airbnb least penetrated markets" (Chapter Five). The elaboration of these two cases follows the same logic of the U.S. case. Firstly, the authors describe the organization of the housing and real estate finance system; secondly, they clarify the effects of the Great Financial Crisis on housing markets; third, they delve into the impact of Airbnb and STRs on specific neighborhoods and housing; lastly, they outline the local regulatory initiatives.

In the conclusions, the authors discuss the challenges STRs' negative externalities bring about for housing and communities, specifically around the themes of housing inequality, urban insecurity, housing, and social stability.

About "Short-term Rentals and the Future of Housing", I found the detailed analysis on the housing systems and markets, and specifically of the upheavals of the GFC, of great interest. This historical approach provides readers with enough information to glimpse why short-term rentals are more or less widespread, more or less regulated in the different case studies. In addition, I appreciated the elaboration on housing tenure models: the importance they give to homeownership and/or rental rates in determining the potential pervasiveness and/or features of short-term rentals is a promising perspective of analysis: a topic which potentially opens an interesting research avenue. On the contrary, I found that the links with financialization and platform capitalism have been vaguely addressed. The authors describe these two aspects as the leading lens of analysis, however the impression is that the interlinkages of STRs with finance, rents, tech and digital platforms (Zukin, 2020) remain here an aspect of the (dis) economy of housing platformization which is never really unpacked, so that, in the end, the work lacks originality.

Furthermore, although there are references to the literature about STRs supply side in the text (such as Fields, 2019, among others), a more structured consideration of economic actors of the STRs market, both corporate and private, and at different scales, would have been useful. How can we consider thinking about the future of short-term rentals if we don't focus in detail on who contributes to the creation of the negative externalities? This is an emerging perspective on STRs actors (Semi \& Tonetta, 2020), which follows the proposal of the authors of Gentrifiers (Schlichtman et al., 2017) and Evicted (Desmond, 2016) who place the study of gentrifiers' and landlords' perspectives at the centre of the understanding of dynamics of housing injustice. Similarly, I was expecting a greater focus on the actors of regulation and legislation too, as they will potentially determine the future of short-term rentals and housing. Regulatory initiatives concerning STRs are also related with the political orientation of the governing institutions, and the diverse forms that regulation can take may emerge as a result of complex negotiations with different actors. For example, regulatory dispositions are also influenced by different lobbying networks, such as grassroots movements (i.e. right to housing social movements, collective initiatives against touristification) and/or category associations (i.e. host associations; landlords associations; hotel lobbies...) present or absent-with their power-in the cities, as it emerges clearly in the works of Novy and Colomb (2019) and Aguilera et al. (2019).

Lastly, a note on the organization of the structure of the book. It is difficult not to notice that the introductory themes of chapter one (briefly summarized above) are gathered under the section devoted to the American experience, although they are obviously general and 
constitute the framework for all the cases. Part one could have been given a wider introductory slant, and part two could have focused on the three case studies, proceeding in a funnel-like logic from the general to the particular. Perhaps I also would have balanced the cases and considered two cities for each case study. I understand that the phenomenon has developed starting in the USA, however, four American cities, two Australian and two German necessarily led to an unbalanced discussion which emerges also considering the number of pages devoted to the two different parts.

Despite the criticisms, I consider "Short-term Rentals and the Future of Housing" as a good introductory book which provides an overview of the main features of the phenomenon. Indeed, I would recommend it especially to those who are approaching the topic for the first time; on the contrary, it brings little novelty for scholars already committed to the debate's advancement.

\section{References}

Aguilera, T., Artioli, F., \& Colomb, C. (2019). Explaining the diversity of policy responses to platformmediated short-term rentals in European cities: A comparison of Barcelona, Paris and Milan. Environment and Planning A: Economy and Space. https://doi.org/10.1177/0308518X19862286

Desmond, M. (2016). Evicted: Poverty and profit in the American city. Broadway Books.

Fields, D. (2019). Automated landlord: Digital technologies and post-crisis financial accumulation. Environment and Planning A: Economy and Space, 8, 212-234.

Novy, J., \& Colomb, C. (2019). Urban tourism as a source of contention and social mobilisations: A critical review. Tourism Planning \& Development, 16(4), 358-375.

Schlichtman, J. J., Patch, J., \& Lamont, H. M. (2017). Gentrifiers. University of Toronto Press.

Semi, G., \& Tonetta, M. (2020). Marginal hosts: Short-term rental suppliers in Turin, Italy. Environment and Planning A: Economy and Space. https://doi.org/10.1177/0308518X20912435

Zukin S. (2020). Seeing like a city: How tech became urban. In Theory and society (pp. 1-24). https://doi. org/10.1007/s11186-020-09410-4.

Publisher's Note Springer Nature remains neutral with regard to jurisdictional claims in published maps and institutional affiliations. 